\title{
FLÂNEUR O VOYEUR: \\ LA AMBIGÜEDAD DE LA FIGURACIÓN DEL YO \\ EN VENTANAS DE MANHATTAN (2004), \\ DE ANTONIO MUÑOZ MOLINA
}

\author{
FLÂNEUR OR VOYEUR: \\ THE AMBIGUITY OF THE FIGURATION OF THE SELF \\ IN ANTONIO MUÑOZ MOLINA'S \\ VENTANAS DE MANHATTAN (2004)
}

\author{
Mieke VULKERS \\ Universidad de Utrecht ${ }^{1}$ \\ m.vulkers@uu.nl
}

Resumen: Generalmente se caracterizan las novelas de Antonio Muñoz Molina como híbridos, o sea, la inserción de géneros no-ficcionales en el marco de una obra novelística. Aunque se presenta Ventanas de Manhattan (2004) solamente como un diario o un libro de viajes, el presente trabajo argumenta que la obra manifiesta una forma genérica híbrida. En base a un marco teórico, se establecen los componentes que llevan a la caracterización de Ventanas de Manhattan como autoficcional. A continuación, este artículo se centra en la construcción del yo como una estructura ficcional, fundada en arquetipos literarios.

Palabras clave: Antonio Muñoz Molina. Ventanas de Manhattan. Autoficción. Construcción del yo. Arquetipo literario.

Abstract: The novels of Spanish author Antonio Muñoz Molina generally are characterized as hybrids, inserting non-fictional genres within the frame of a novelistic work. Although Ventanas de Manhattan (2004) is

\footnotetext{
${ }^{1}$ Agradezco la lectura atenta de los profesores E.M.H. Houvenaghel, L. García-Manso y C. Navarrete Rodríguez.
} 
presented as a diary or even as a travelling journal, this article argues that the work shows a hybrid generic form. Founded upon a theoretical frame, it establishes the components that lead to the characterization of the work as autofictional. Subsequently this article focuses on the construction of the first-person character as a fictional structure, based on literary archetypes.

Key Words: Antonio Muñoz Molina. Ventanas de Manhattan. Autofiction. Construction of the self. Literary archetype.

\section{INTRODUCCIÓN}

En la obra novelesca de Antonio Muñoz Molina (1956) el hibridismo narrativo, la confluencia de (sub)géneros diferentes en una novela, se manifiesta como una característica preponderante. Más en concreto, se califica la mayoría de las novelas del autor como correspondiente en mayor o menor medida con la forma de hibridismo denominada autoficción: "un tipo de híbrido narrativo que amalgama la ficción y la autobiografía" (Ibáñez Ibáñez, 2014: 95). Sin embargo, la obra Ventanas de Manhattan (2004) se presenta como si perteneciera a un solo subgénero de índole autobiográfica: el del diario. En otras ocasiones, la obra aparece recomendada como un libro de viajes, subrayando el aspecto de las vivencias reales del autor. Cada uno de dichos propósitos parece responder a una época en la que "lo privado se ha hecho público", por lo que los textos autobiográficos "despiertan una atracción especial de curiosidad e interés en la sociedad 'voyeurista' en la que vivimos" (Burguete Pérez, 2009: 66). No obstante, proponemos que Ventanas de Manhattan también se puede clasificar, a pesar de los paratextos y las presentaciones publicitarias, como una obra autoficcional, ya que se establece una amalgama de autobiografía y ficción en la obra.

Además, la elección de la autoficción está fundada en una motivación personal relacionada con la interpretación profesional del autor. Ciertos elementos genéricos y temáticos de Ventanas de Manhattan parecen regresar en la obra más reciente del autor, Un andar solitario entre la gente (2018). De ahí que el presente trabajo aborde el análisis de Ventanas de Manhattan centrándose en los rasgos genéricos de la obra y la construcción del yo. De esta manera, contestaremos a las siguientes preguntas: ¿Cuáles son los componentes que inducen al carácter 
autoficcional de la obra Ventanas de Manhattan de Antonio Muñoz Molina? y ¿cómo se manifiesta la figuración del yo? Comenzaremos explorando las teorías literarias acerca del género autobiográfico y de la hibridez de la autoficción. A continuación, estableceremos la clasificación genérica de la obra y analizaremos la representación del yo en Ventanas de Manhattan, para llegar, finalmente, a una conclusión acerca de la relación entre ambos aspectos.

\section{DE LA LITERATURA AUTOBIOGRÁFICA A LA AUTOFICCIÓN: LÍMITES GENÉRICOS Y MANIFESTACIONES DEL YO}

Desde los años setenta del siglo XX, el uso del concepto de la autobiografía ha producido cierta confusión en el ámbito de la teoría literaria, ya que se ha utilizado el término tanto en relación con el género literario de la escritura autobiográfica como con respecto al subgénero de la autobiografía en sentido estricto. Coincidimos con Romera Castillo al referirnos a la escritura autobiográfica, en sentido amplio, como un género literario que se divide en distintos tipos o subgéneros. Entre dichos subgéneros se hallan la autobiografía auténtica, las memorias y el diario (1981: 52-54). Romera Castillo formula las siguientes características como las condiciones genéricas de la literatura autobiográfica:

[E]l yo del escritor queda plasmado en la escritura como un signo referencial de su propia existencia; existe una identificación del narrador y del héroe de la narración; el relato debe abarcar un espacio temporal suficiente para dejar rastros de la vida [...]; el discurso empleado [...] será el narrativo [...]; y el sujeto del discurso se plantea como tema de la narración sincera [...] de su existencia pasada a un receptor... (1981: 14).

Ahora bien, abordemos el subgénero de la literatura autobiográfica que estimamos relevante en el marco de nuestro análisis: el diario. El término autobiografía supone, por el elemento etimológico bios, que significa vida, la escritura de una vida en su conjunto, mientras que la palabra diario se refiere a día, por lo que "el diario trata aspectos diarios" (Romera Castillo, 1981: 53). Por su parte, Philippe Lejeune afirma que 
la perspectiva temporal es la diferencia decisiva entre la autobiografía auténtica y el diario. Según él, la autobiografía auténtica asume el relato retrospectivo y el diario se sitúa en el presente (1975: 20). Romera Castillo matiza el aspecto temporal, enfatizando que el diario abarca sólo veinticuatro horas, por lo que se centra en un pasado más reciente de corta duración. La perspectiva retrospectiva reducida intensifica la cualidad de proximidad y realidad; no obstante, se pierde la distancia reflexiva y analítica (Romera Castillo, 1981: 54). Por otro lado, "los diarios son la quintaesencia de la literatura íntima", en los que el escritor produce una memoria estrictamente personal, anotando observaciones y juicios de sus vivencias por medio de "actos de escritura coetáneos" (Romera Castillo, 1981: 46).

En resumen, consideramos el diario como un subgénero literario, en el que el escritor se manifiesta en el texto y es narrador y protagonista al mismo tiempo. Además, se divide el texto en unidades diarias que plasman las vivencias del autor, presentadas como narraciones sinceras. Dado que Ventanas de Manhattan se ha interpretado como un diario, utilizaremos las características mencionadas para establecer en qué medida la obra se corresponde con dicho subgénero.

La autoficción, por su parte, no se define como un (sub)género literario, sino que ocupa una posición específica dentro del hibridismo narrativo, a saber: la manifestación literaria que florece con el surgimiento de la posmodernidad. La particularidad híbrida de la autoficción consiste en que se forma por dos componentes determinados: la autobiografía y la ficción; asimismo, se distinguen algunas formas particulares de presentarse.

Al definir el hibridismo narrativo como todo tipo de mezcla de la novela con otros (sub)géneros literarios o las demás formas de expresión, consideramos la autoficción el híbrido en el que confluyen el uso de los recursos novelísticos y la escritura autobiográfica. Pozuelo Yvancos remite a la acepción originaria de autoficción, acuñada por Serge Doubrovsky en su novela Fils (1977). Señala que el escritor francés sitúa la distinción entre la autobiografía y la autoficción en que la última presenta fragmentos sueltos de una vida que no se percibe como una totalidad, mientras que la autobiografía cumple una función explicativa y unificadora (Pozuelo Yvancos, 2010: 12). Pozuelo Yvancos se refiere asimismo a la tesis doctoral de Colonna, quien define la autoficción como "une oeuvre littéraire par 
laquelle un écrivain s'invente une personnalité et une existence, tout en conservant son identité réelle (son véritable nom)" (Colonna, 1989: 30).

Alberca subraya en su estudio El pacto ambiguo (2007) también la relevancia de la identificación, afirmando que "[1]as autoficciones tienen como fundamento la identidad visible o reconocible del autor, narrador y personaje del relato" (2007: 31), lo que lleva a la identificación nominal entre autor real, narrador y protagonista (2007: 224). Por último, Casas menciona en "La autoficción en los estudios hispánicos: perspectivas actuales" (2014) algunas modalidades de la autoficción en la literatura hispánica contemporánea, de las cuales mencionamos tres, en relación con nuestra investigación: el relato "centrado en la experiencia personal, pero narrado con los recursos de la novela" y "la [modalidad] que se cruza con el relato testimonial donde los elementos ficcionales colaboran en la construcción de la memoria y los valores morales" (2014: 11). Además, se refiere a la metaficción como un rasgo dominante de la autoficción, ya que el autor, escribiendo sobre su propia vida, se muestra propenso a describir su oficio, así como el proceso de escribir la obra misma.

Concebimos, por tanto, la autoficción como una obra literaria en la que el autor, a pesar de la identificación de su persona real con el narrador y el personaje, presenta el relato fragmentado de una existencia que además puede ser inventado. En el marco de nuestro análisis, destacamos también la relevancia de los siguientes principios: el uso de los recursos novelísticos, la construcción de los valores morales y el papel de la metaficción.

En el ámbito de la escritura autobiográfica, al igual que en el marco de la representación autoficcional, el yo se manifiesta de manera específica, lo que se origina principalmente en la ambigüedad del personaje. Como ya observamos, la escritura autobiográfica requiere la presencia del autor real, cuyo nombre se encuentra en la cubierta, en el texto (Lejeune, 1975: 23-24). Sin embargo, en los estudios más recientes se distingue otro aspecto de la escritura autobiográfica, que se corresponde con la capacidad de construir el personaje del yo, por lo que contribuye al carácter paradójico del fenómeno del yo autobiográfico. Darío Villanueva, en "Para una pragmática de la autobiografía" (1991), afirma que la escritura autobiográfica posee, además de la dimensión referencial, la "virtualidad creativa", que sirve para la construcción de la identidad del yo, en vez de para su reproducción (1991: 108). Es decir; la personificación del yo de la literatura autobiográfica es una entidad ficticia, construida por el autor 
mismo.

En segundo lugar, el autor real, cuya presencia en el texto es la precondición de la escritura autobiográfica, no sólo puede coincidir con el narrador-protagonista de la narración - la condición formal de la autobiografía auténtica (Lejeune, 1975: 15)—, sino que también tiene la oportunidad de manifestarse mediante la tercera persona, lo que funciona como una "máscara tras la que el escritor se esconde" (Romera Castillo, 1981: 14-15). En este caso, muchas veces ya nos encontramos en el espacio de "los relatos autobiográficos de ficción" (Romera Castillo, 1981: 14). Sin embargo, la autoficción dispone de otras vías más que inducen a la figuración del yo. Como Ibáñez Ibáñez afirma, los escritores de las novelas autoficcionales no se conforman con las reglas y prescripciones que limitan el género de la literatura autobiográfica, sino que han trocado el yo en "una metáfora textual sobre la que operan [...]" (2014: 94). Por tanto, el carácter ficticio del yo autobiográfico, ya señalado en el párrafo anterior, obtiene un papel más amplio en la escritura autoficcional, como se observa a continuación:

El yo no es, pues, el de las autobiografias tradicionales: testimoniamos una absoluta reconstrucción de este que permite, con la sola variante del texto, repetir al infinito la misma experiencia y por tanto, múltiples posibilidades de ser, en perfecta sincronía con la percepción dual y subjetivista del individuo en la actualidad [...]. En consecuencia la autoficción permite, y es una de sus aportaciones más relevantes, la multiplicación del yo... (Ibáñez Ibáñez, 2014: 97).

En la concepción de Pozuelo Yvancos, quien subraya la importancia de la visión discontinua de la autoficción, se representa el yo mediante "la fragmentación del sujeto" a la cual se refiere como "corps morcelé" (2010: 15). En este contexto, Pozuelo Yvancos introduce el término figuración del yo, definiéndolo como la "representación de un yo figurado de carácter personal" (2010: 22). Subraya que la figuración del yo no necesariamente coincide con la autoficción, dado que "puede adoptar formas de representación distintas a la referencialidad biográfica o existencial" (Pozuelo Yvancos, 2010: 22).

Partiendo de la idea de que, por medio de la autoficción, el autor 
puede crear versiones diferentes y fragmentadas de sí mismo, analizaremos la representación del yo en Ventanas de Manhattan. Particularmente, nos centraremos en cómo se relaciona el yo referencial de la escritura autobiográfica con su manifestación ficticia, expresada de manera construida.

\section{LA HIBRIDACIÓN GENÉRICA EN VENTANAS DE MANHATTAN}

Ante la hibridación genérica, tanto el autor como el crítico literario se enfrentan con el problema de etiquetar el producto literario mediante un término adecuado. No sólo el título diario parece ser insuficiente para determinar el (sub)género literario de Ventanas de Manhattan, sino que calificarlo de autoficción tampoco resulta satisfactorio. Al investigar la producción literaria de Antonio Muñoz Molina, notamos que la bibliografía de Wikipedia presenta tanto Ventanas de Manhattan como Días de diarios (2007), bajo el epígrafe "Diarios"'. Por otra parte, la editorial Seix Barral edita la obra en la colección Booket "Biblioteca Antonio Muñoz Molina" como una novela y el catálogo de Casa del Libro la categoriza como un "libro de viajes". Analizando el género de Ventanas de Manhattan, las reseñas prometen que nos entretendremos con "una fusión de testimonio, autobiografía y narración" (Sanz Villanueva, 2004: s. p.) donde "no faltan elementos de ficción, recuerdos de estancias anteriores" (Doria, 2004: 48).

Por su parte, Antonio Muñoz Molina no se pronuncia claramente en relación con el género del libro, ya que en su sitio web comenta la obra de la siguiente manera: "una escritura de observación y viaje, de crónica y recuerdo, sin argumento, sin género preciso". Además, el autor afirmó, en una entrevista reproducida por María Burguete Pérez, que "Ardor guerrero y Ventanas de Manhattan no tienen nada de ficción. El primero es autobiografía pura: el segundo es una cosa híbrida entre la memoria personal y el libro de viajes" (Burguete Pérez, 2009: 707). De ahí que el historiador Justo Serna (2014), experto de la obra de Muñoz Molina, ni siquiera preste atención a Ventanas de Manhattan en un análisis reciente del trabajo novelesco del autor. Ibáñez Ibáñez (2014), en su tesis sobre el

\footnotetext{
${ }^{2}$ Véase la entrada de Wikipedia de Antonio Muñoz Molina: https://es.wikipedia.org/wiki/ Antonio_Mu\%C3\%Bloz_Molina [22/04/2019].
} 
híbrido narrativo en la novela de Antonio Muñoz Molina, tampoco incluye la obra entre las trece novelas que analiza.

Ahora bien, a pesar de la confusión de términos, comencemos nuestro análisis partiendo de la caracterización simple de la obra como diario, para ampliar a continuación la visión hacia la autoficción. Las vivencias del protagonista, relatadas por el narrador homodiegético, se muestran idénticas a las peripecias del autor, puesto que encontramos algunas referencias reconocibles a la persona de Muñoz Molina en la realidad. Como, por ejemplo, su presencia en Nueva York en los tiempos del ataque a las Torres Gemelas y las actividades profesionales de escritor y de director del Instituto Cervantes. Los sucesos asimismo están relatados sinceramente, como los episodios sobre los atentados del 11 de septiembre de 2001, presentados en forma de reportajes por medio de un testigo. De ahí que concluyamos que nos encontramos dentro del ámbito de la literatura autobiográfica.

No obstante, el relato se presenta más bien por medio de episodios coherentes de corta duración, sin ajustarse únicamente a una regularidad diaria. Además, se comienza la narración con una reconstrucción del primer viaje del autor a Nueva York, una analepsis hacia la iniciación en la ciudad, escrita en el tiempo pasado; sólo a partir del capítulo once se vuelve definitivamente al presente de la narración. De esta manera, el autor dispone de la posibilidad de contemplar y comparar los episodios previos ocurridos en Manhattan. Por tanto, rechazamos la caracterización de la obra como un diario en sentido estricto, denominándola una hibridación con rasgos de autobiografía auténtica y diario.

Conviene tener en cuenta que el propio Muñoz Molina ya alude a la hibridez de la obra, sugeriendo, como anotamos más arriba, que es "una cosa híbrida entre la memoria personal y el libro de viajes" (Burguete Pérez, 2009: 707). En una entrevista con Miguel Barrero habla de Ardor Guerrero (1995), explicando que se basa en el ámbito literario anglosajón al utilizar la palabra memoria. Como el singular de memoirs (memorias), el autor se refiere a memoria como sigue: el escritor elige un periodo o una experiencia concreta de su vida, que cuenta en primera persona, utilizando los recursos del arte narrativo, pero sin ficción (Centro Niemeyer, 2013: 24.13-24.56 min.). No obstante, en el caso de Ventanas de Manhattan detectamos ciertos rasgos de ficcionalización que llevan a la caracterización de la obra como autoficción, lo que demostraremos a continuación. 
En el marco de la determinación del carácter autoficcional de la obra, es preciso examinar si el conjunto híbrido de índole autobiográfica que caracterizamos anteriormente confluye con la ficción. Aunque ya concluímos que Ventanas de Manhattan se encuentra dentro de los confines de la literatura autobiográfica, no se explicita la identificación nominal entre autor real, narrador y protagonista. En la obra se hallan ciertos indicios que muestran que la complejidad de la obra va más allá del (sub)género autobiográfico. Como afirma el escritor mismo: "[e]n cada caso pretendo [...] encontrar la mejor correspondencia posible entre el material que tengo entre manos y el modo de contar" (Burguete Pérez, 2009: 707). Es decir, aunque el autor niega que Ventanas de Manhattan sea ficción (Burguete Pérez, 2009: 707), a su vez construye una forma literaria estética para que la memoria personal se exprese óptimamente.

En primer lugar, Muñoz Molina utiliza los recursos narrativos, como la analepsis, con el fin de crear un marco temporal contrastante que da relieve a la narración situada en el presente. Además, como analizaremos más adelante, el escritor se recrea en el tema de la ventana, acentuado por el título de la obra, que sirve de fundamento para la construcción ficcional, mediante el uso repetido de la ventana como elemento situacional y metafórico. En segundo lugar, inserta reflexiones que contienen valoraciones éticas o artísticas, por lo que se resaltan las peripecias que forman la memoria personal. Concretamente, algunos capítulos parecen más bien ensayos sobre arte, abordando el tema de las ventanas de Nueva York en las pinturas de Hopper y de Katz (Muñoz Molina, 2004: 57-63, 63-68). Por último, el autor se sitúa junto a la ventana de un café Starbucks o en Central Park con "los instrumentos livianos de [su] oficio, las pocas cosas elementales que necesit[a], un cuaderno y un rotulador, y nada más", y se retrata a sí mismo como "un literato antiguo de provincias" (2004: 163). Por tanto, el autor se presenta durante el proceso de creación de la obra misma, por lo que se manifiesta el carácter metaficcional de la obra.

En definitiva, establecemos que Ventanas de Manhattan contiene las características del género híbrido de la autoficción, ya que presenta una mezcla de la modalidad autobiográfica y la ficción. Apreciamos los rasgos de la autoficción, mencionados por Casas, como el uso de los recursos narrativos, la inserción de observaciones reflexivas y la metaficción (2014: 11). Sin embargo, aparte de la autoficción, encontramos rasgos propios a otros (sub)géneros como el ensayo y el reportaje. La diversidad genérica 
se refleja en una multiplicación del yo que analizaremos en la sección siguiente.

\section{FIGURACIONES DEL YO ENTRE EL ROBINSON URBANO Y EL HOMBRE-EN-LA-VENTANA}

La autoficción le permite al escritor desdoblar el yo por medio de la presencia simultánea de la imagen del autor real y la construcción ficticia del yo. Además de transformarse a lo largo de la obra, el personaje del escritor construido en Ventanas de Manhattan adopta dos formas reconocibles, que se refieren a las proyecciones del yo de obras anteriores: el Robinson urbano y el hombre-en-la-ventana.

Igualmente, obtenemos una visión de la vida diaria del yo real mediante los reportajes de la actualidad, particularmente cuando relata los acontecimientos del 11-S: "ahora la luz del sol está oscurecida, como tamizado por un filtro ocre. Cuesta respirar y se nota enseguida un picor en la garganta. La gente, en la acera, camina tapándose la boca con mascarillas y pañuelos" (Muñoz Molina, 2004: 92). El autor añade sus reflexiones acerca de esta actualidad, cuando explica: "Camino aturdido y extranjero entre la gente y no sé cuál es la realidad, si lo que escucho en la radio que llevo pegada al oído o lo que estoy viendo con mis ojos..." (2004: 86-87). En este caso, prima la forma del reportaje por la necesidad de compartir una experiencia y dar testimonio de un momento histórico. No obstante, el autor real también construye en otros momentos una figuración de sí mismo, una forma manipulada a través de los recursos narrativos, como veremos más adelante.

Ya vimos en la sección anterior que Muñoz Molina se retrata a sí mismo cuando llega por primera vez a Nueva York, trece años antes del presente de la escritura, en los capítulos iniciales de Ventanas de Manhattan:

Mi cosmopolitismo novelero de transeúnte solo en Nueva York se trasmutó velozmente en aprieto de palurdo cuando intenté pagar el trayecto con un billete y el conductor, un negro grande con cara de fastidio [...], me dijo algo que yo no llegaba a entender, porque el sobresalto de vergüenza me cerraba todavía más los oídos ineptos (2004: 18). 
Corbellini comenta los primeros episodios de la siguiente manera: "Estas escenas en el inicio del libro se proponen como la prehistoria del personaje, que prepara el desarrollo de la novela, para cuando será evidente el cambio en la escritura del autor" (2010: 156). También opina que "las imágenes y sensaciones que entonces no tenían lógica ni sentido hoy se configuran en un análisis profundo de la cultura americana" (2010: 154). Ya se puede observar el desarrollo de la representación del yo en el capítulo nueve, cuando ha llegado su amada a la ciudad y el protagonista decide regalarle "[sus] lugares más queridos de Nueva York a la mujer que iba con [él]" (2004: 45). En efecto, la transformación del visitante torpe en un habitante de la metrópoli de Nueva York, subraya la re-figuración del autor de sí mismo que demuestra que no es una figura unidimensional.

La primera versión figurada del yo que se manifiesta repetidamente durante las caminatas por las calles de Manhattan es el Robinson urbano, la figura preferida del autor ya desde los artículos tempranos que publicó en 1982 en el Diario de Granada bajo el epígrafe "El Robinson urbano". Lo describe de la siguiente manera: "A Robinson lo que le importa no es encontrarse, sino perderse y huir, cambiar de nombre, usar la máscara del Carnaval..." (Muñoz Molina, 1984: 36). Es decir, el Robinson urbano es el hombre que se sumerge en la muchedumbre de la ciudad, con el fin de experimentar, observar y escuchar la vida diaria, pasando desapercibido.

Delineado así, el Robinson urbano se compara con el flâneur ${ }^{3}$, el personaje literario arquetípico que surgió en el ámbito de la literatura francesa del siglo XIX. El filósofo alemán Walter Benjamin (1892-1940) ya comenta al flâneur, incluyendo los análisis de la obra del poeta francés Baudelaire (1821-1867) en sus observaciones de la vida moderna. Según Ruiz Rico, "el flâneur mira y pasea, y en ese viaje [...] narra la ciudad, la funda y se funde con ella, la imagina, la inventa..." (2011: 65). Muñoz Molina propone en Ventanas de Manhattan que "[e]l gusto de estar en Nueva York es inseparable del alivio de no estar en España, de no vivir agobiado por las noticias y las obsesiones de cada día" (2004: 119). El autor se siente libre de las otras obligaciones y puede coleccionar el material de su escritura. Como "[e]n Nueva York, la soledad más extrema

${ }^{3}$ Muñoz Molina también le otorga un papel central al flâneur en su obra del año 2018, Un andar solitario entre la gente. 
puede encontrarse en medio de una multitud" (2004: 123):

[e]l nómada en Manhattan es más nómada solitario que casi en ninguna otra parte, porque estará perfectamente solo en lo más espeso de una muchedumbre, y porque nadie reparará en él [...]. El nómada, si acaso, se reconoce en quienes circulan tan sin destino como él, en los chalados y en los vagabundos... (2004: 179)

El yo construido por Muñoz Molina necesita escaparse a una ciudad donde nadie lo conoce, así como el actor español Javier, a quien se encuentra allí, protagonista en una serie de televisión exitosa, disfrutando en Manhattan "el placer recobrado y paradójico del anonimato" (2004: 298). No obstante, para el escritor la evasión no sólo es una necesidad personal, "soy más yo mismo que nunca, más que en cualquier otra parte" (2004: 341), sino también un instrumento profesional, porque durante los paseos urbanos "los sentidos en acción, en estado de alerta" (2004: 176) le permiten percibir los olores de la ciudad y "las ráfagas de una conversación" (2004: 178).

La segunda figuración del yo, el emblema temático de la obra, es el hombre que se asoma a la ventana para observar la vida callejera. Se acerca a la mirada obsesiva de la figura arquetípica del voyeur, aunque sea sin las conotaciones de aberración sexual. Podemos considerarlo una derivación del Robinson urbano, dado que, como él, utiliza las observaciones como material de trabajo. Por otro lado, como mantiene la distancia por medio de la frontera del cristal, el contacto sensorial es menos directo. El hombreen-la-ventana, ocupándose de las imágenes de la ciudad, es analítico y reflexivo, por lo que lo calificamos como figura complementaria a la del Robinson urbano:

[...] por la ventana del apartamento [...] se ve una acera neutra con pequeñas acacias, la esquina de un edificio moderno que da a Lincoln Square y el ancho ventanal de un aula de la Juilliard School of Music, donde suele haber atriles con partituras, y donde músicos jóvenes [...] tocan instrumentos que yo no llego nunca a escuchar... (Muñoz Molina, 2004: 78-79).

Es decir, además de permitir una mirada desde el interior, las 
ventanas de Manhattan revelan "en cada edificio, como en capítulos o estampas diversas, las vidas y las tareas de quienes habitan al otro lado" (2004: 56). Apreciamos no sólo las ventanas reales de las habitaciones y los cafés de Manhattan, sino también las ventanas metafóricas de los cuadros, descritos en las digresiones ensayísticas, que muestran a menudo otras ventanas, descubriendo de esta manera el efecto del espejo doble. El autor describe un cuadro de Hopper de la siguiente manera: "[una casa con] una ventana que permanece iluminada en la noche, y hacia la que mira alguien, detrás de la que parece que hay alguien mirando hacia el exterior, dedicado a una vigilia insomne" (2004: 61).

Muñoz Molina establece un paralelismo entre los cuadros de Hopper y los cuentos de Cornell Woolrich que Alfred Hitchcock adaptó a la película Rear Window (1954). El protagonista de Rear Window, el fotógrafo L.B. Jeffries, interpretado por James Steward, adopta "el rol de 'voyeur', pero con el acercamiento formal al acto fotográfico y con unas referencias [...] que dejan constancia de su estatus como reportero" (Parejo Jiménez, 2004: 110). Dada la localización de la película en Manhattan y la posición observadora de Jeffries, podemos advertir la analogía con el hombre-en-la-ventana de Muñoz Molina. Al mismo tiempo, percibimos que la relevancia de la mirada, plasmada metafóricamente por el concepto de la ventana, queda subrayada por los varios capítulos dedicados a la fotografía, con referencias al fotógrafo Richard Avedon (Muñoz Molina, 2004: 279-284) y a las fotos encontradas en el rastro de los domingos en Manhattan (2004: 320-323).

Otra manifestación de las ventanas sobre el mundo son los libros, siempre los compañeros de la proyección literaria del autor. En Manhattan, donde aprende la lengua inglesa, la lectura le induce a Muñoz Molina a experimentar "las incitaciones que esos libros despiertan en [él]" (2004: 344). Por tanto, concluimos que el hombre-en-la-ventana, además de observar, desea leer con el fin de aprender, acumulando de esta manera el material de su propia escritura. O bien, como explica el escritor en "El argumento y la historia" (1998): "En el origen del acto de escribir está el gusto de mirar y aprender..." (Muñoz Molina, 1998: 28). A nuestro modo de ver, la construcción del yo se refleja en el hibridismo genérico de la obra. El escritor Antonio Muñoz Molina vive en un mundo polifacético que se relaciona tanto con la realidad urbana como con el ámbito ficticio de la escritura. Utiliza la multitud de la ciudad para escapar y esconderse, 
una necesidad tanto personal como profesional, con el fin de coleccionar las experiencias que fundan su producción literaria.

Con Ventanas de Manhattan, Muñoz Molina produce una obra híbrida, donde da forma al yo de maneras distintas. Por un lado, proyecta una imagen del autor real, la actitud del escritor trasluciéndose mediante la representacion de sus vivencias al caminar en la ciudad, registrando lo que experimenta. Por otro lado, ficcionaliza el yo, subrayando su desarrollo a lo largo del tiempo y desdoblándolo en dos figuras complementarias. La síntesis del Robinson urbano y el hombre-en-la-ventana, que representa lo experimental junto con la observacion, manifiesta la esencia del ser del personaje del escritor, y de Muñoz Molina en realidad. Subrayamos que la elección de las figuras emblemáticas del flâneur y del voyeur se basa en la urgencia de la estetización y actualización de los arquetipos literarios. Además, cada uno de ellos, el Robinson urbano, el hombre-en-la-ventana y el escritor Muñoz Molina, necesitan escapar y esconderse para poder vivir, saber y escribir. De ahí que la figuración del yo en Ventanas de Manhattan se encuentre siempre a mitad de camino entre la realidad y la ficción. Antonio Muñoz Molina, el autor real de Ventanas de Manhattan, es escritor de novelas, de obras autobiográficas, de artículos periodísticos y de ensayos de temática cultural y artística. Además, durante la escritura de la obra, se encuentra en Nueva York, ciudad por excelencia de la muchedumbre, trabajando de director del Instituto Cervantes. La complejidad de esta existencia se manifiesta en su literatura mediante una multitud de géneros, no sólo en la totalidad de su obra, sino también en el hibridismo narrativo de novelas concretas como Ventanas de Manhattan. En esta obra se muestra el realismo de los géneros de la autobiografía, el reportaje, representado por el testimonio en relación con el 11-S, y el ensayo, mediante las referencias al arte pictórico. Las muestras de las vivencias del autor se mezclan con la construcción literaria del yo, el énfasis en los valores morales y el estilo metaficcional. Consideramos la opción del hibridismo en el sentido más amplio inherente a la necesidad profesional del escritor: una multitud de (sub)géneros le permite expresar la pluralidad que experimenta. Al mismo tiempo responde a un impulso personal: le posibilita esconderse, en este caso en una muchedumbre literaria.

A nuestro modo de ver, el deseo de escapar y esconderse se corresponde con una necesidad del escritor en la que lo personal y lo profesional aparecen inseparables: el deseo de experimentar, saber y 
escribir. Por tanto, la elección de la autoficción, mezcla de realidad personal y ficción, nos parece inherente a esta predisposición, que se refleja particularmente en la presentación ambigua del yo.

\section{CONCLUSIÓN}

Tras considerar la autoficción como una forma híbrida compuesta por la mezcla entre autobiografía y ficción, hemos establecido el carácter autoficcional de Ventanas de Manhattan de Antonio Muñoz Molina. En primer lugar, demostramos los rasgos autobiográficos de la obra, comprobando la identidad de autor, narrador y personaje. A pesar de que no se presenta la identificación nominal del autor en el texto, la realidad de la persona del escritor se manifiesta por medio de las referencias reconocibles a la vida de Muñoz Molina. Mejor que un diario, caracterizamos la obra como un híbrido autobiográfico, que además muestra ciertos rasgos pertenecientes a la ficción. Sin embargo, no sólo destacan algunas características específicas de la autoficción (el uso de los recursos narrativos, la construcción de la memoria y los valoras morales, y la metaficción) sino también señales de un hibridismo genérico a través de la amalgama de la ficción con el ensayo y el reportaje. Como consecuencia de la autoficción, la figuración del yo se presenta de manera ambigua, dividida entre lo referencial y lo ficcional. Se construye una imagen del protagonista, situándolo en el tiempo mediante algunos episodios analépticos, por lo que advertimos el desarrollo del personaje. Al mismo tiempo, se duplica el yo en dos figuras complementarias, el Robinson urbano y el hombre-en-la-ventana, retratadas repetidamente para que percibamos los constituyentes principales de la figuración del yo. Apreciamos el carácter literario de los dos arquetipos en los que se basa la figuración del yo, el flâneur y el voyeur, por lo que se observa la búsqueda de estetización del autor. Además, ambas figuras, a pesar de que se prolongan hacia el exterior con el fin de experimentar y aprender, guardan una distancia que les permite digerir la información obtenida y convertirla en literatura. Ventanas de Manhattan presenta un yo que escapa a Nueva York para poder desaparecer, aprovechando el anonimato de la gran ciudad para obtener la mejor manifestación de sí mismo y experimentar óptimamente la vida urbana. Se asoma a la ventana, de forma real y metafórica, impulsado por el deseo personal así como profesional 
de observar y conocer el mundo. Opinamos que la realidad multiforme de la vida del escritor le induce a optar por un estilo literario que refleja esa multitud: el hibridismo narrativo. La predisposición del escritor, la amalgama del deseo individual y la necesidad profesional de saber y compartir, se convierte en un conjunto inseparable de la realidad personal y la ficción. Por tanto, a nuestro modo de ver, la autoficción se presenta como la alternativa imprescindible dentro del hibridismo narrativo para moldear la obra ficcional de Antonio Muñoz Molina.

\section{REFERENCIAS BIBLIOGRÁFICAS}

ALBERCA, M. (2007). El pacto ambiguo. De la novela autobiográfica a la autoficción. Madrid: Biblioteca Nueva.

BARRERO, M. (e.1.). "Ciclo de la palabra. Encuentro con Antonio Muñoz Molina". CentroNiemeijer, https://www.youtube.com/watch? $v=f$ 2 KxmVrdt4\& $t=2834 s$ [10/05/2018].

BURGUETE PÉREZ, M. (2009) La retórica del dietario en Antonio Muñoz Molina. Tesis doctoral: Universidad de Zaragoza.

CASAS, A. (2014). "La autoficción en los estudios hispánicos: perspectivas actuales". En El yo fabulado: nuevas aproximaciones críticas a la autoficción, Ana Casas (ed.), 7-21. Madrid / Frankfurt am Main: Iberoamericana Vervuert.

COLONNA, V. (1989). L'autofiction (essai sur la fictionalisation de soi en Littérature). Tesis de doctorado: École des Hautes Études en Sciences Sociales, https://tel.archives-ouvertes.fr/tel-00006609/ document [06/06/2018].

CORBELlini, N. (2010). Trayectoria poética de Antonio Muñoz Molina. Tesis de doctorado: Universidad Nacional de La Plata, http:// www.fuentesmemoria.fahce.unlp.edu.ar/tesis/te.366/te.366.pdf [02/02/2017].

DORIA, S. (2004). "Asomarse y sentir vértigo". Revista de libros de la Fundación Caja Madrid 88, 48.

IBÁÑEZ IBÁÑEZ, M. (2014). El "híbrido narrativo" en la novela de Antonio Muñoz Molina. Tesis doctoral: Universidad de la Rioja, Servicio de Publicaciones.

LEJEUNE, PH. (1975). Le pacte autobiographique. Paris: Éditions du 
Seuil.

MUÑOZ MOLINA, A. (2016 [1984]). El Robinson urbano. Barcelona: Seix Barral.

(1998) "El argumento y la historia". En Pura alegría, 21-35. Madrid: Alfaguara.

(2016 [2004]). Ventanas de Manhattan. Barcelona: Seix Barral.

(s. f.). [Sección de] "Publicaciones". Web oficial de Antonio Muñoz Molina, http://antoniomuñozmolina.es/publicaciones/ [03/03/2017].

PAREJO JIMÉNEZ, N. (2004). "La comunicación a través de la mirada: las dificultades de aprehender la realidad". Comunicar. Revista Científica de Comunicación y Educación 29.XV, 109-114.

POZUELO YVANCOS, J. M. (2010). "“Figuración del yo' frente a autoficción". En su obra, Figuraciones del yo en la narrativa: Javier Marías y Enrique Vila-Matas, 11-35. Valladolid: Cátedra Miguel Delibes.

ROMERA CASTILLO, J. (1981). "La literatura, signo autobiográfico: El escritor, signo referencial de su escritura". En La literatura como signo, José Romera Castillo (ed.), 13-56. Madrid: Editorial Playor.

RUIZ RICO, M. (2011). Antonio Muñoz Molina. El Robinson en Nueva York. Sevilla: CAL.

SANZ VILLANUEVA, S. (2004). "Ventanas de Manhattan". El Cultural, 19 de febrero (también en https://www.elcultural.com/revistal letras/Ventanas-de-Manhattan/8882 [22/04/2019]).

SERNA, J. (2014). Antonio Muñoz Molina: El tiempo en nuestras manos. Madrid: Fórcola.

VILLANUEVA, D. (1991). "Para una pragmática de la autobiografía". En su obra, El polen de ideas, 95-115. Barcelona: PPU.

Recibido el 9 de enero de 2019.

Aceptado el 3 de abril de 2019. 